\title{
Vedolizumab Therapy Is Associated with an Improvement in Sleep Quality and Mood in Inflammatory Bowel Diseases
}

\author{
Betsy W. Stevens ${ }^{1}$, Nynke Z. Borren ${ }^{1,2}$, Gabriella Velonias ${ }^{1}$, Grace Conway ${ }^{1}$, Thom \\ Cleland $^{1}$, Elizabeth Andrews ${ }^{1}$, Hamed Khaliili ${ }^{1,3}$, John G. Garber ${ }^{1,3}$, Ramnik J. Xavier ${ }^{1,3}$, \\ Vijay Yajnik $^{1,3}$, and Ashwin N. Ananthakrishnan ${ }^{1,3}$
}

${ }^{1}$ Division of Gastroenterology, Massachusetts General Hospital Crohn's and Colitis Centre, 165 Cambridge Street, 9th Floor, Boston, MA 02114, USA 2University of Groningen, Groningen, The Netherlands ${ }^{3}$ Harvard Medical School, Boston, MA, USA

\begin{abstract}
Introduction-Poor sleep, depression, and anxiety are common in patients with inflammatory bowel diseases (IBD) and associated with increased risk of relapse and poor outcomes. The effectiveness of therapies in improving such psychosocial outcomes is unclear but is an important question to examine with increasing selectivity of therapeutic agents.

Methods-This prospective cohort enrolled patients with moderate-to-severe CD or UC starting biologic therapy with vedolizumab or anti-tumor necrosis factor a agents (anti-TNF). Sleep quality, depression, and anxiety were measured using validated short-form NIH PROMIS questionnaires assessing sleep and mood quality over the past 7 days. Disease activity was assessed using validated indices. Improvement in sleep and mood scores from baseline was assessed, and regression models were used to identify determinants of sleep quality.
\end{abstract}

Results-Our study included 160 patients with IBD (49 anti-TNF, 111 Vedolizumab) among whom half were women and the mean age was 40.2 years. In the combined cohort, we observed a statistically significant and meaningful decrease in mean scores from baseline (52.8) by week 6 (49.8, $p=0.002)$. Among vedolizumab users, sleep T-score improved from baseline (53.6) by week 6 (50.7) and persisted through week $54(46.5, p=0.009)$. Parallel reductions in depression and anxiety were also noted ( $p<0.05$ by week 6 ). We observed no difference in improvement in sleep, depression, and anxiety between vedolizumab and anti-TNF use at week 6.

Conclusions-Both vedolizumab and anti-TNF biologic therapies were associated with improvement in sleep and mood quality in IBD.

Correspondence to: Ashwin N. Ananthakrishnan.

Betsy W. Stevens and Nynke Z. Borren equally contributed as first authors.

Electronic supplementary material The online version of this article (doi:10.1007/s10620-016-4356-2) contains supplementary material, which is available to authorized users.

Author contributions Stevens, Borren, Velonias, Conway, Cleland, Andrews, Khalili, Garber, Xavier, and Yajnik: study design, data collection, analysis and interpretation of data, drafting of the manuscript, and critical revision of the manuscript for important intellectual content. Ananthakrishnan: study design, data collection, analysis and interpretation of data, drafting of the manuscript, critical revision of the manuscript for important intellectual content, and study supervision.

Conflict of interest Ananthakrishnan has served on scientific advisory boards for Abbvie, Takeda, and Merck. 


\section{Keywords}

Vedolizumab; Sleep; Biologics; Depression; Anxiety

\section{Introduction}

With a growing incidence worldwide, inflammatory bowel diseases (IBD) affect an estimated 1.5 million people in the USA [1,2]. Crohn's disease (CD) and ulcerative colitis (UC), collectively comprising IBD, are chronic inflammatory conditions primarily involving the gastrointestinal tract but exerting a range of extra-intestinal influences. Characterized by periods of remission and relapse, the natural history of IBD is often complicated and frequently requires hospitalizations and surgeries [3]. In addition to physical manifestations, IBD has a major impact on health-related quality of life, impacting an individuals' career, relationships, and mental health [4-6]. Depression, anxiety, and stress are common in patients with IBD and their role as environmental influences on the pathogenesis and course of IBD is still being explored [5, 7-10]. Existing research shows that stress, coping, depression, and anxiety may increase risk of CD and UC [11-13] and contribute to symptomatic relapses, hospitalizations, and surgeries [14-18].

An important but understudied extra-intestinal symptom in patients with IBD is impairment of sleep. There likely exists a bidirectional association between sleep and inflammation such that active disease and elevations in inflammatory markers may contribute to poor sleep [1922], while impaired sleep quality, in turn, may increase severity of clinical and histologic inflammation and risk of clinical relapse [23, 24]. Prior studies have shown that patients with IBD are more likely to have sleep deprivation when compared to healthy individuals, more commonly in those with clinically active disease but also in those in remission [25, 26]. Regardless of disease activity, sleep disturbance exerts a significant negative impact on patients' quality of life [27].

Advances in therapeutics offer us increasingly effective medications to attain clinical and endoscopic remission [28, 29]. Immunosuppression, the cornerstone of long-term maintenance therapy in moderate-to-severe CD and UC, was initially achieved through broadly acting agents such as thiopurines or methotrexate [30-32], but evolved to more precise targets such as monoclonal antibodies targeting tumor necrosis factor a (anti-TNF; infliximab, adalimumab, certolizumab, golimumab) $[33,34]$ and more recently gut-selective anti-integrin therapy (vedolizumab) $[35,36]$. Systemic anti-TNF medications have demonstrated significant efficacy in treating extra-intestinal symptoms including improvement in sleep and depression [37-40]. Whether such effects are mediated through an improvement in disease activity alone or additionally by a direct central nervous system effect is unknown [38]. Consequently, it is important to examine whether gut-selective therapy with vedolizumab can also similarly ameliorate sleep disturbances, depression, and anxiety in patients with IBD.

Consequently, we performed this study with the following aims: (1) To examine changes in sleep quality, depression, and anxiety after initiation of vedolizumab therapy for moderateto-severe CD and UC; (2) To identify determinants of sleep quality at baseline and 
improvement of sleep quality with therapy; and (3) To compare changes in sleep, depression, and anxiety with vedolizumab to anti-TNF therapy.

\section{Methods}

\section{Study Cohort}

This prospective cohort study was nested within the Prospective Registry for IBD Study at Massachusetts General Hospital (PRISM). Details of this cohort have been previously published [41-43]. For the purpose of this study, all patients receiving care at the Crohn's and Colitis center at Massachusetts General Hospital and commencing therapy with vedolizumab (vedolizumab cohort) or anti-TNF therapy (adalimumab, infliximab, certolizumab, or golimumab) (anti-TNF cohort) for CD and UC were approached for inclusion between May 2014 and March 2016. Eligible subjects were at least 18 years of age, had a confirmed diagnosis of CD or UC, and were initiating outpatient therapy with one of the above agents according to routine clinical care. Upon providing consent, all patients completed an enrollment interview with a trained research coordinator where demographics, disease, and treatment history including current and past medications were noted and confirmed by medical record review.

\section{Study Protocol and Follow-Up}

All patients initiated therapy with an anti-TNF agent (infliximab or adalimumab) or vedolizumab according to standard induction and maintenance dosing. Study assessments were performed at weeks $0,2,6,14,22,30$, and 54. Data collected at each interval included sleep quality and mental health as outlined below and disease activity according to the Harvey Bradshaw Index (HBI) for CD and Simple Clinical Colitis Activity Index (SCCAI) for UC, and health-related quality of life assessed using the Short Inflammatory Bowel Disease Questionnaire (SIBDQ) [44-46]. Clinical remission was defined as an HBI $\leq 4$ or a SCCAI $\mathcal{s}$. Whenever available (usually at every infusion), levels of serum C-reactive protein (CRP) and erythrocyte sedimentation rate (ESR) were collected. Patients on selfadministered adalimumab injection completed study questionnaires within a 4-week window of each of the above time points in addition to a week 14 evaluation.

\section{Study Outcomes: Sleep, Depression, and Anxiety}

All enrolled patients were invited to complete questionnaires regarding sleep and mood quality using the short-form National Institute of Health Patient-Reported Outcome Measurement Information System for sleep disturbance, depression, and anxiety [47, 48]. Questionnaires from the PROMIS bank for sleep disturbance, depression, and anxiety have shown validity in multiple prior studies $[49,50]$. Sleep quality was assessed using an 8 -item NIH PROMIS questionnaire assessing sleep disturbance over the past 7 days. This yields a continuous score which is translated to a T-score ranging from 28.9 (best) to 76.5 (worst sleep quality). Depression and anxiety over the past 7 days were examined similarly with an 8-item questionnaire with T-scores ranging from 38.2 to 81.3 and 37.1 to 83.1, respectively. As a reference, a mean NIH PROMIS T-score corresponds to a value of 50; a deviation of 10 represents one standard deviation away from the mean. In our study, patients with a T-score

Dig Dis Sci. Author manuscript; available in PMC 2018 January 01. 
above 50 were considered as having disturbed sleep, significant depressive, or anxiety symptoms.

\section{Statistical Analysis}

All statistical analysis was performed using Stata 13.1 (StataCorp, College Station, TX). Continuous variables were summarized using means and standard deviations and compared using the $t$ test if normally distributed or the Mann-Whitney- $U$ test if skewed. Categorical variables were expressed as proportions and compared using the Chi-square test with the Fisher's exact modification when appropriate. Week 0 estimates comprised the baseline values for all patients, while the primary follow-up visit was at week 14. First, we defined factors impacting sleep quality at baseline by performing univariate linear regression analysis with demographic, disease-related, and psychosocial parameters. Multivariable models were then constructed including variables significant in the univariate analysis at $p<$ 0.05. A forward-stepwise approach was used for the multivariable models, retaining variables as being independently significant at a two-sided $p$ value $<0.05$. Next, we examined the change in sleep quality with initiation of therapy. Sleep, depression, and anxiety T-scores assessed at different study visits were compared with values at start of therapy at week 0 , stratifying by whether the patients were on vedolizumab or anti-TNF therapy. In the cohort of individuals with no missing baseline or follow-up data, we compared the sleep, depression, and anxiety T-scores at each follow-up point (week 6, 14, 30 , and 54) to baseline values using the paired $t$ test. Finally, we examined the association between sleep, depression, and anxiety and attainment of clinical response (defined as a 3point improvement in HBI or SCCAI) or remission $(\mathrm{SCCAI}<2$ or $\mathrm{HBI}<4)$ at week 14. Patients with a stoma or an ileal pouch-anal anastomosis (IPAA) were not included in assessments of disease activity.

The study was approved by the Institutional Review Board of Massachusetts General Hospital.

\section{Results}

\section{Study Cohort}

Of the 183 patients with IBD (104 CD, 79 UC) included in the cohort, 52 patients ( $28 \%)$ were started on anti-TNF therapy (infliximab or adalimumab) and 131 patients $(72 \%)$ started vedolizumab. After excluding patients who had missing sleep score both at baseline and week 14 follow-up ( $n=23)$, we arrived at the final cohort of 160 patients ( 49 anti-TNF, 111 vedolizumab). Patients excluded were similar to the final cohort in age, sex, treatment type (anti-TNF or vedolizumab), type of IBD, disease activity, insomnia, or depressive disorders but were slightly more likely to have anxiety and taking immunomodulators. A total of 117, 93, and 110 patients provided data on sleep quality at baseline, week 6 and week 14, respectively. Half the cohort was women $(50 \%)$ with a mean age at enrollment of 40.2 years. Eight patients had an ileoanal pouch and 12 had a stoma. Patients receiving antiTNF therapy were similar to those on vedolizumab in sex and type of IBD, a medical history of insomnia, depression and anxiety, current medication use, and CRP level (Table 1).

Dig Dis Sci. Author manuscript; available in PMC 2018 January 01. 
Patients receiving vedolizumab were slightly older, had a longer duration of disease, had a higher HBI at baseline, and were more likely to have previously tried an anti-TNF therapy.

\section{Factors Associated with Sleep Disturbance at Baseline}

Table 2 presents univariate comparisons of factors impacting sleep at baseline. Both depression $(p=0.002)$ and anxiety $(p<0.001)$ were associated with worse sleep quality at baseline. A baseline depression T-score $>50$ and an anxiety T-score $>50$ were associated with a 5- and 6-point worse sleep T-score compared to individuals without significant depression or anxiety symptoms. Higher disease activity was also associated with worse sleep with each 1-point increase in HBI or SCCAI worsening the sleep T-score by 0.53 ( $p=$ $0.026)$. Other variables associated with sleep on univariate analysis were current smoking ( $p$ $=0.036)$, use of opioids $(p=0.046)$, and need for sleep aids $(p=0.009)$. Use of corticosteroids, 5-aminosalicylates, or immunomodulators did not demonstrate significant associations with the sleep T-score. There was no significant difference in sleep disturbance T-score at baseline between anti-TNF and vedolizumab users $(p=0.136)$.

On multivariable analysis, the strongest factor independently associated with sleep T-score was the presence of anxiety [Regression co-efficient $(\beta) 7.14 ; 95 \%$ confidence interval (CI), $3.36-10.92]$, while opioid use showed a trend toward significance $(\beta 5.02 ; 95 \% \mathrm{CI},-0.30$ to 10.34). Disease characteristics and baseline disease activity were not associated with worse sleep quality on adjusted analysis. Sensitivity analysis with the raw sleep score as the outcome or dichotomizing at a sleep T-score of 50 yielded similar results (data not shown).

\section{Change in Sleep and Mood with Biologic Treatment}

In the combined cohort, the sleep disturbance T-score showed an early improvement in the 84 patients who had both sleep T-score at baseline and follow-up, showing a statistically significant and meaningful decrease in mean scores by week 6 [52.8 \pm 9.7 (week 0 ) to 49.8 $\pm 9.4, p=0.002]$. At the week 14 analysis which included 67 patients, the sleep T-score continued to show a significant improvement compared to baseline [52.6 \pm 10.1 (week 0 ) to $49.2 \pm 8.8, p=0.002]$.

Analysis of vedolizumab users alone showed a similar early significant improvement in sleep disturbance T-score by week 6 ( $n=56$ patients) ( $50.7 \pm 10.3, p=0.013)$, continuing to week 14 ( $n=52$ patients) $(49.0 \pm 8.4, p=0.003)$ (Fig. 1$)$. The mean sleep T-score continued to remain lower at week $30(n=37)(49.6 \pm 9.9, p=0.006)$ and at week $54(n=13)(46.5$ $\pm 9.6, p=0.009)$ when compared to baseline. Analysis of anti-TNF users alone also showed a trend toward reduction in sleep score between baseline and week $6(n=28)(51.4 \pm 9.4-$ $48.1 \pm 7.3, p=0.069$ ). That only a small number of patients had sleep measured at week 14 precluded meaningful statistical analysis, but the estimates were numerically lower compared to baseline $(n=15,50.1 \pm 10.1, p=0.447)$ (Fig. 1$)$. Among anti-TNF users, a statistically significant reduction in depression scores was noted from baseline (50.1) to week $6(48.1, p=0.02)$ and week $14(49.4, p=0.058)$ though only 19 patients contributed to the week 14 time point (Supplemental Figure 1). The change in anxiety T-scores did not reach statistical significance at either of the two time points. 
In parallel with the improvement in sleep quality in vedolizumab, we noted a significant improvement in depression and anxiety T-scores as well (Fig. 2). Depression T-score showed a 3-point decrease in mean by week $6(52.3 \pm 10.8-49 \pm 10.6)$, a 4.5-point decrease at week $14(47.8 \pm 9.0)$, and an even greater long-term improvement at week $30(46.9 \pm 8.9)$ and week $54(45.8 \pm 8.0)$. Although anxiety symptoms were more likely at baseline in comparison with depression symptoms, a similar result was noted with an early improvement by week $6(54.3 \pm 10.7-50.6 \pm 10.9)$ and week 14 (49.0 \pm 10.1$)$. Long-term improvement in anxiety was reported as well by week $30(48.5 \pm 10.5)$ and continued with a 6-point decrease at week $54(48.3 \pm 9.6)$.

\section{Association Between Disease Activity and Sleep}

The clinical outcomes of patients in our cohort are provided in Table 3 . Nearly half the patients attained clinical remission at week 14 (48\%). Clinical status at week 14 was a strong determinant of sleep and mood. Patients with continued active disease were more likely to have disturbed sleep (T-score >50) $(56 \%)$ in comparison with patients who were in remission $(30 \%)(p=0.01)$. They were also more likely to have depression $(47 \%)$ and anxiety (56\%) symptoms compared to those in remission (18 and $34 \%$, respectively) ( $p<$ 0.05 for both). On multivariable analysis, persistence of depressive symptoms $(\beta 6.85 ; 95 \%$ $\mathrm{CI}, 3.08-10.63, p=0.001)$ and ongoing disease activity $(\beta 0.62 ; 95 \% \mathrm{CI}, 0.11-1.14, p=$ $0.019)$ were independent predictors of disturbed sleep on follow-up.

\section{Discussion}

Crohn's disease and ulcerative colitis are complex, immunologically mediated diseases leading to considerable physical impairment, and need for hospitalizations and surgery. However, their impact extends beyond physical manifestations alone to psychosocial impairment and decrease in health-related quality of life that are influenced strongly but not exclusively by disease activity. Impairment of sleep and mood are important but understudied extra-intestinal complications of $\mathrm{CD}$ and $\mathrm{UC}$, significantly affecting patients functioning. Therapies such as anti-TNF and anti-integrin biologic therapies have demonstrated significant efficacy in achieving clinical remission from symptoms, mucosal healing endoscopically, and reducing the need for surgery and hospitalizations. However, the effect of treatments on extra-intestinal and psychosocial outcomes is poorly studied but becomes increasingly important as therapies evolve to more gut-selective targeted immunosuppression. In a rigorously conducted prospective cohort study, we demonstrate that both vedolizumab and anti-TNF biologic therapies were associated with a significant improvement in sleep, depression, and anxiety within 6 weeks of initiation of therapy and that such improvements were sustained up to at least 1 year.

While disease activity is an important determinant of mood and sleep in patients with IBD, prior studies have shown significant sleep disturbance in patients with IBD even in the absence of clinically active disease. In a small study, Ranjbaran et al. demonstrated that even in the setting of inactive disease, overall subjective sleep quality was worse and sleep interruptions were frequent in patients with IBD compared to healthy controls [25, 27]. In other prospective cohorts, $48 \%$ of patients in remission had a sleep T-score greater than [24,

Dig Dis Sci. Author manuscript; available in PMC 2018 January 01. 
50] and sleep disruption was independent of the presence of nocturnal symptoms [22]. One hypothesis proposed for this is that circulating inflammation markers themselves directly may have a central effect, leading to disturbed sleep. Elevated CRP, IL-1, IL-6, and TNF-a levels have been found in patients with sleep disturbances [19, 21, 22, 51]. IL-6 has been reported to reduce REM sleep and increases wakefulness in patients, where IL-1 and TNF-a increase spontaneous sleep and the sleep rebound that occurs after sleep deprivation [52, 53]. Thus, hypothetically anti-inflammatory therapy could decrease the circulating inflammatory cytokines and improve the sleep quality in IBD patients. Few prior studies have examined the impact of such therapy in other autoimmune diseases and none in IBD. One study evaluated sleep deprivation and the effects of anti-TNF therapy on sleep deprivation in ankylosing spondylitis patients and noted a clear correlation between sleep disturbance and disease activity [54]. However, no significant difference in sleep quality was found between patients using anti-TNF agents and controls. In contrast, Taylor-Gjevre et al. [55] recognized an improved sleep efficiency and awakening after sleep onset time in rheumatoid arthritis patients treated with anti-TNF therapy.

Similar to that observed for sleep quality, we also noted an improvement in both depression and anxiety with both vedolizumab and anti-TNF therapies. A bi-directional association between stress or depression and gut inflammation has been proposed in prior studies, explained by both the effect of depression on circulating inflammation as well as potentially through its influence on the gut microbiome. In a mouse model, depression was induced by mice in which colitis had been established and was in remission [56]. After induction, a reactivation of colitis was observed via the nicotinic receptor $(a 7 n A c h R)$ on macrophages. These macrophages also demonstrated increased pro-inflammatory cytokine secretion suggesting an association between depression and gut inflammation [56]. Supporting this relationship, Howren et al. [57] found that depression was associated with increased levels of IL-1, IL-6, and CRP. While several studies have demonstrated an improvement in overall health-related quality of life with anti-TNF biologic treatment, few have examined the effect of such therapies directly on depression and anxiety, and none with vedolizumab. Horst et al. [58] showed in a small sample size study that immunosuppressive therapy decreased depression scores significantly. Another study found similar results after starting infliximab infusions but noted that patients with a current or past depressive disorder at baseline had a higher immune activation as well [59]. It is reassuring to both patients and providers that early and sustained improvement in sleep quality and mood were noted with both gutselective anti-integrin therapy and systemic anti-TNF therapy in our cohort, leading to the hypothesis that a reduction in disease burden and circulating inflammation, rather than only a direct central effect, may be contributing to improvement in these parameters with treatment.

Multiple prior studies have assessed risk factors for poor sleep, depression, or anxiety in $\operatorname{IBD}[5,8,11,24,27,60]$. Predictors of sleep quality in our study were similar to those previously noted. Interestingly, we found that use of opioids showed a trend toward an association with poor sleep quality which represents a novel association, potentially mediated through disease severity, and chronic pain. Previous studies have demonstrated that health-related quality of life was markedly lower in patient who used opioids for treatment of their IBD [61, 62]. However, no other study has reported such a correlation between 
opioid use and sleep quality. This finding serves as an added incentive for patients to avoid long-term opioid use in patients with IBD.

There are a few implications to our findings. To our knowledge, our study represents the first attempt to quantify the effects of biologic treatment, vedolizumab and anti-TNF agents, on sleep quality and mood in IBD patients. While resolution of physical symptoms, endoscopic healing, and prevention of bowel damage are key targets in the management of IBD, psychosocial symptoms are nevertheless important determinants of health-related quality of life and well-being. It is important to include such assessments as structured endpoints in both observational cohorts and clinical trials to ensure that not only is resolution of the intestinal consequences of inflammation achieved but also a comparable improvement in the psychosocial consequences of disease. This attains particular importance with increasing selectivity of therapeutic targets as a significant proportion of patients with IBD experience such symptoms such as disrupted sleep, anxiety, depression, or fatigue. Such studies in conjunction with translational research will aid in understanding the mechanisms behind such symptoms in patients with IBD, thus making it possible to have effective directed treatments that improve such outcomes.

We acknowledge several limitations with our study include the lack of objective measurement of sleep such as polysomnography and a relatively small sample size though it represents the largest observational cohort to date assessing such outcomes. As it was based on a referral center, our population may be skewed toward more severe disease. Third, while sleep and mood measurements were available in the vast majority of patients, not all patients had paired values both at baseline and week 14 (though the missing data were random). As in an observational study, there may be the effect of unmeasured confounders. We also did not have information on steroid dose and sleep aid use at each of the time points, and their impact on sleep quality.

In conclusion, we observed a significant improvement in sleep and mood quality in IBD patients after initiation of biologic therapy with vedolizumab or anti-TNF agents. Continued research is needed to understand the exact etiology of such symptoms in patients with IBD. Assessment of depression, anxiety, and sleep should become a part of routine IBD clinical care owing to their impact on quality of life, and interventional studies comparing effectiveness of different IBD therapies in improving such parameters are important to ensure optimal patient outcomes.

\section{Supplementary Material}

Refer to Web version on PubMed Central for supplementary material.

\section{Acknowledgments}

Funding This work is supported by the National Institutes of Health (NIH) (P30 DK043351) to the Center for Study of Inflammatory Bowel Diseases. Ananthakrishnan is supported in part by a Grant from the National Institutes of Health (K23 DK097142). 


\section{References}

1. Abraham C, Cho JH. Inflammatory bowel disease. N Engl J Med. 2009; 361:2066-2078. [PubMed: 19923578]

2. Molodecky NA, Soon IS, Rabi DM, et al. Increasing incidence and prevalence of the inflammatory bowel diseases with time, based on systematic review. Gastroenterology. 2012; 142:46-54 e42. quiz e30. [PubMed: 22001864]

3. Bernstein CN, Loftus EV Jr, Ng SC, et al. Hospitalisations and surgery in Crohn's disease. Gut. 2012; 61:622-629. [PubMed: 22267595]

4. Graff LA, Vincent N, Walker JR, et al. A population-based study of fatigue and sleep difficulties in inflammatory bowel disease. Inflamm Bowel Dis. 2011; 17:1882-1889. [PubMed: 21830266]

5. Graff LA, Walker JR, Bernstein CN. Depression and anxiety in inflammatory bowel disease: a review of comorbidity and management. Inflamm Bowel Dis. 2009; 15:1105-1118. [PubMed: 19161177]

6. Hommes D, Colombel JF, Emery P, et al. Changing Crohn's disease management: need for new goals and indices to prevent disability and improve quality of life. J Crohns Colitis. 2012; 6:S224S234. [PubMed: 22463929]

7. Hauser W, Janke KH, Klump B, et al. Anxiety and depression in patients with inflammatory bowel disease: comparisons with chronic liver disease patients and the general population. Inflamm Bowel Dis. 2011; 17:621-632. [PubMed: 20848528]

8. Walker JR, Ediger JP, Graff LA, et al. The Manitoba IBD cohort study: a population-based study of the prevalence of lifetime and 12-month anxiety and mood disorders. Am J Gastroenterol. 2008; 103:1989-1997. [PubMed: 18796096]

9. Kurina LM, Goldacre MJ, Yeates D, et al. Depression and anxiety in people with inflammatory bowel disease. J Epidemiol Community Health. 2001; 55:716-720. [PubMed: 11553654]

10. Ananthakrishnan AN. Environmental risk factors for inflammatory bowel disease. Gastroenterol Hepatol (N Y). 2013; 9:367-374. [PubMed: 23935543]

11. Ananthakrishnan AN, Khalili H, Pan A, et al. Association between depressive symptoms and incidence of Crohn's disease and ulcerative colitis: results from the Nurses' Health Study. Clin Gastroenterol Hepatol. 2013; 11:57-62. [PubMed: 22944733]

12. Lerebours E, Gower-Rousseau C, Merle V, et al. Stressful life events as a risk factor for inflammatory bowel disease onset: a population-based case-control study. Am J Gastroenterol. 2007; 102:122-131. [PubMed: 17100973]

13. Tocchi A, Lepre L, Liotta G, et al. Familial and psychological risk factors of ulcerative colitis. Ital J Gastroenterol Hepatol. 1997; 29:395-398. [PubMed: 9494844]

14. Singh S, Graff LA, Bernstein CN. Do NSAIDs, antibiotics, infections, or stress trigger flares in IBD? Am J Gastroenterol. 2009; 104:1298-313. quiz 1314. [PubMed: 19337242]

15. Bernstein CN, Singh S, Graff LA, et al. A prospective population-based study of triggers of symptomatic flares in IBD. Am J Gastroenterol. 2010; 105:1994-2002. [PubMed: 20372115]

16. Ananthakrishnan AN, Gainer VS, Perez RG, et al. Psychiatric comorbidity is associated with increased risk of surgery in Crohn's disease. Aliment Pharmacol Ther. 2013; 37:445-454. [PubMed: 23289600]

17. Gaines LS, Slaughter JC, Horst SN, et al. Association between affective-cognitive symptoms of depression and exacerbation of Crohn's disease. Am J Gastroenterol. 2016; 111:864-870. [PubMed: 27045927]

18. Mikocka-Walus A, Pittet V, Rossel JB, et al. Symptoms of depression and anxiety are independently associated with clinical recurrence of inflammatory bowel disease. Clin Gastroenterol Hepatol. 2016; 14:829-835 e1. [PubMed: 26820402]

19. Haack M, Sanchez E, Mullington JM. Elevated inflammatory markers in response to prolonged sleep restriction are associated with increased pain experience in healthy volunteers. Sleep. 2007; 30:1145-1152. [PubMed: 17910386]

20. Uthgenannt D, Schoolmann D, Pietrowsky R, et al. Effects of sleep on the production of cytokines in humans. Psychosom Med. 1995; 57:97-104. [PubMed: 7792381]

Dig Dis Sci. Author manuscript; available in PMC 2018 January 01. 
21. Vgontzas AN, Papanicolaou DA, Bixler EO, et al. Elevation of plasma cytokines in disorders of excessive daytime sleepiness: role of sleep disturbance and obesity. J Clin Endocrinol Metab. 1997; 82:1313-1316. [PubMed: 9141509]

22. Wilson RG, Stevens BW, Guo AY, et al. High C-reactive protein is associated with poor sleep quality independent of nocturnal symptoms in patients with inflammatory bowel disease. Dig Dis Sci. 2015; 60:2136-2143. [PubMed: 25701321]

23. Ali T, Madhoun MF, Orr WC, et al. Assessment of the relationship between quality of sleep and disease activity in inflammatory bowel disease patients. Inflamm Bowel Dis. 2013; 19:2440-2443. [PubMed: 23945186]

24. Ananthakrishnan AN, Long MD, Martin CF, et al. Sleep disturbance and risk of active disease in patients with Crohn's disease and ulcerative colitis. Clin Gastroenterol Hepatol. 2013; 11:965971. [PubMed: 23376797]

25. Keefer L, Stepanski EJ, Ranjbaran Z, et al. An initial report of sleep disturbance in inactive inflammatory bowel disease. J Clin Sleep Med. 2006; 2:409-416. [PubMed: 17557469]

26. Ananthakrishnan AN, Khalili H, Konijeti GG, et al. Sleep duration affects risk for ulcerative colitis: a prospective cohort study. Clin Gastroenterol Hepatol. 2014; 12:1879-1886. [PubMed: 24780288]

27. Ranjbaran Z, Keefer L, Farhadi A, et al. Impact of sleep disturbances in inflammatory bowel disease. J Gastroenterol Hepatol. 2007; 22:1748-1753. [PubMed: 17914945]

28. Baumgart DC, Sandborn WJ. Crohn's disease. Lancet. 2012; 380:1590-1605. [PubMed: 22914295]

29. Ordas I, Eckmann L, Talamini M, et al. Ulcerative colitis. Lancet. 2012; 380:1606-1619. [PubMed: 22914296]

30. Sandborn WJ, Feagan BG, Lichtenstein GR. Medical management of mild to moderate Crohn's disease: evidence-based treatment algorithms for induction and maintenance of remission. Aliment Pharmacol Ther. 2007; 26:987-1003. [PubMed: 17877506]

31. Chande N, Patton PH, Tsoulis DJ, et al. Azathioprine or 6-mercaptopurine for maintenance of remission in Crohn's disease. Cochrane Database Syst Rev. 2015; :CD000067.doi: 10.1002/14651858.CD000067.pub3 [PubMed: 26517527]

32. McDonald JW, Wang Y, Tsoulis DJ, et al. Methotrexate for induction of remission in refractory Crohn's disease. Cochrane Database Syst Rev. 2014; :CD003459.doi: 10.1002/14651858.CD003459.pub4 [PubMed: 25099640]

33. Danese S, Vuitton L, Peyrin-Biroulet L. Biologic agents for IBD: practical insights. Nat Rev Gastroenterol Hepatol. 2015; 12:537-545. [PubMed: 26284562]

34. D'Haens G, Daperno M. Advances in biologic therapy for ulcerative colitis and Crohn's disease. Curr Gastroenterol Rep. 2006; 8:506-512. [PubMed: 17105690]

35. Feagan BG, Rutgeerts P, Sands BE, et al. Vedolizumab as induction and maintenance therapy for ulcerative colitis. N Engl J Med. 2013; 369:699-710. [PubMed: 23964932]

36. Sandborn WJ, Feagan BG, Rutgeerts P, et al. Vedolizumab as induction and maintenance therapy for Crohn's disease. N Engl J Med. 2013; 369:711-721. [PubMed: 23964933]

37. Weinberger JF, Raison CL, Rye DB, et al. Inhibition of tumor necrosis factor improves sleep continuity in patients with treatment resistant depression and high inflammation. Brain Behav Immun. 2015; 47:193-200. [PubMed: 25529904]

38. Zamarron C, Maceiras F, Mera A, et al. Effect of the first infliximab infusion on sleep and alertness in patients with active rheumatoid arthritis. Ann Rheum Dis. 2004; 63:88-90. [PubMed: 14672898]

39. Ersozlu-Bozkirli ED, Keskek SO, Bozkirli E, et al. The effect of infliximab on depressive symptoms in patients with ankylosing spondylitis. Acta Reumatol Port. 2015; 40:262-267. [PubMed: 25702318]

40. Vavricka SR, Schoepfer A, Scharl M, et al. Extraintestinal Manifestations of Inflammatory Bowel Disease. Inflamm Bowel Dis. 2015; 21:1982-1992. [PubMed: 26154136]

41. Ananthakrishnan AN, Cagan A, Cai T, et al. Common genetic variants influence circulating vitamin D levels in inflammatory bowel diseases. Inflamm Bowel Dis. 2015; 21:2507-2514. [PubMed: 26241000] 
42. Pringle PL, Stewart KO, Peloquin JM, et al. Body mass index, genetic susceptibility, and risk of complications among individuals with Crohn's disease. Inflamm Bowel Dis. 2015; 21:2304-2310. [PubMed: 26181430]

43. Ananthakrishnan AN, Huang H, Nguyen DD, et al. Differential effect of genetic burden on disease phenotypes in Crohn's disease and ulcerative colitis: analysis of a North American cohort. Am J Gastroenterol. 2014; 109:395-400. [PubMed: 24419484]

44. Harvey RF, Bradshaw JM. A simple index of Crohn's-disease activity. Lancet. 1980; 1:514. [PubMed: 6102236]

45. Walmsley RS, Ayres RC, Pounder RE, et al. A simple clinical colitis activity index. Gut. 1998; 43:29-32. [PubMed: 9771402]

46. Irvine EJ, Zhou Q, Thompson AK. The Short Inflammatory Bowel Disease Questionnaire: a quality of life instrument for community physicians managing inflammatory bowel disease. CCRPT Investigators. Canadian Crohn's Relapse Prevention Trial. Am J Gastroenterol. 1996; 91:1571-1578. [PubMed: 8759664]

47. Buysse DJ, Yu L, Moul DE, et al. Development and validation of patient-reported outcome measures for sleep disturbance and sleep-related impairments. Sleep. 2010; 33:781-792. [PubMed: 20550019]

48. Yu L, Buysse DJ, Germain A, et al. Development of short forms from the PROMIS sleep disturbance and sleep-related impairment item banks. Behav Sleep Med. 2011; 10:6-24. [PubMed: 22250775]

49. Kappelman MD, Long MD, Martin C, et al. Evaluation of the patient-reported outcomes measurement information system in a large cohort of patients with inflammatory bowel diseases. Clin Gastroenterol Hepatol. 2014; 12:1315-1323 e2. [PubMed: 24183956]

50. Schalet BD, Pilkonis PA, Yu L, et al. Clinical validity of PROMIS depression, anxiety, and anger across diverse clinical samples. J Clin Epidemiol. 2016; 73:119-127. [PubMed: 26931289]

51. Irwin MR, Wang M, Campomayor CO, et al. Sleep deprivation and activation of morning levels of cellular and genomic markers of inflammation. Arch Intern Med. 2006; 166:1756-1762. [PubMed: 16983055]

52. Krueger JM, Obal FJ, Fang J, et al. The role of cytokines in physiological sleep regulation. Ann N Y Acad Sci. 2001; 933:211-221. [PubMed: 12000022]

53. Krueger JM, Rector DM, Churchill L. Sleep and cytokines. Sleep Med Clin. 2007; 2:161-169. [PubMed: 19098992]

54. Karadag O, Nakas D, Kalyoncu U, et al. Effect of anti-TNF treatment on sleep problems in ankylosing spondylitis. Rheumatol Int. 2012; 32:1909-1913. [PubMed: 21448640]

55. Taylor-Gjevre RM, Gjevre JA, Nair BV, et al. Improved sleep efficiency after anti-tumor necrosis factor alpha therapy in rheumatoid arthritis patients. Ther Adv Musculoskelet Dis. 2011; 3:227233. [PubMed: 22870481]

56. Ghia JE, Blennerhassett P, Deng Y, et al. Reactivation of inflammatory bowel disease in a mouse model of depression. Gastroenterology. 2009; 136:2280-2288. e1-4. [PubMed: 19272381]

57. Howren MB, Lamkin DM, Suls J. Associations of depression with C-reactive protein, IL-1, and IL-6: a meta-analysis. Psychosom Med. 2009; 71:171-186. [PubMed: 19188531]

58. Horst S, Chao A, Rosen M, et al. Treatment with immunosuppressive therapy may improve depressive symptoms in patients with inflammatory bowel disease. Dig Dis Sci. 2015; 60:465470. [PubMed: 25274158]

59. Guloksuz S, Wichers M, Kenis G, et al. Depressive symptoms in Crohn's disease: relationship with immune activation and tryptophan availability. PLoS One. 2013; 8:e60435. [PubMed: 23544139]

60. Ali T, Orr WC. Sleep disturbances and inflammatory bowel disease. Inflamm Bowel Dis. 2014; 20:1986-1995. [PubMed: 25025716]

61. Targownik LE, Nugent Z, Singh H, et al. The prevalence and predictors of opioid use in inflammatory bowel disease: a population-based analysis. Am J Gastroenterol. 2014; 109:16131620. [PubMed: 25178702]

62. Sanford D, Thornley P, Teriaky A, et al. Opioid use is associated with decreased quality of life in patients with Crohn's disease. Saudi J Gastroenterol. 2014; 20:182-187. [PubMed: 24976282]

Dig Dis Sci. Author manuscript; available in PMC 2018 January 01. 

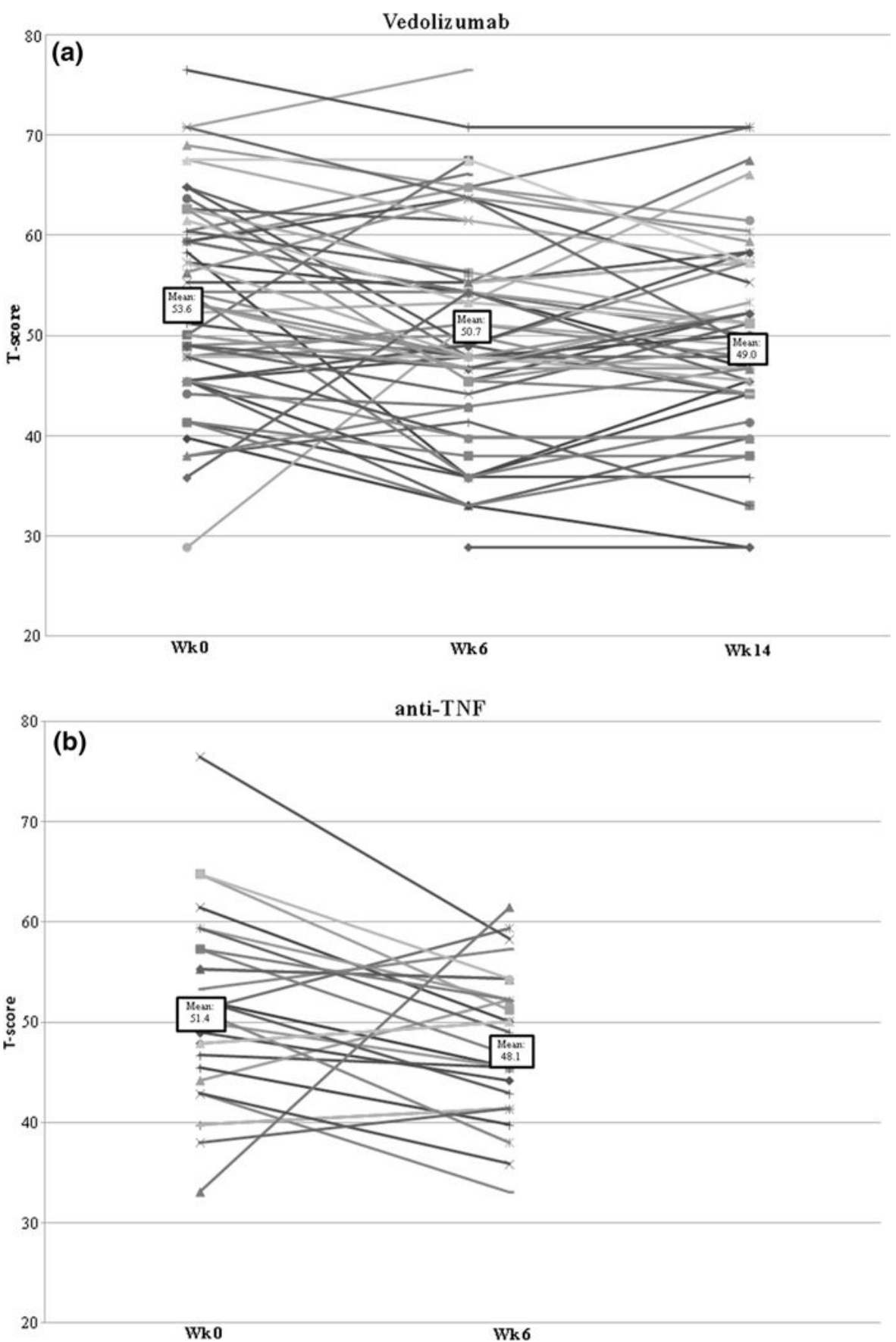

Fig. 1.

Scatter plot demonstrating change in sleep T-scores between baseline, week 6, and week 14 in vedolizumab and anti-TNF users. a Vedolizumab. b Anti-TNF biologics (infliximab, adalimumab) 


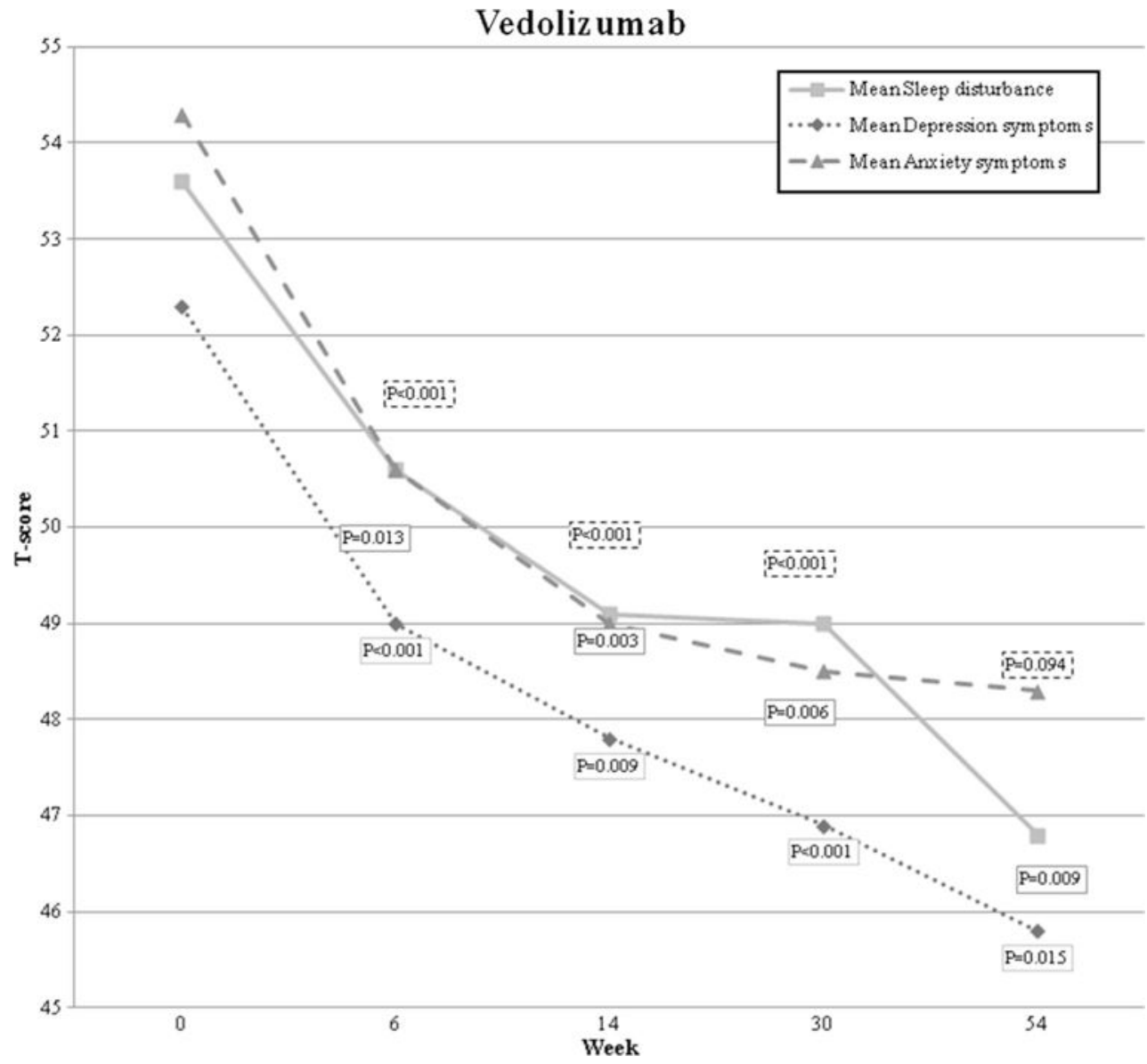

Fig. 2.

Temporal changes in sleep quality, depression, and anxiety with vedolizumab use through week 54. $p$ values represent comparison with baseline (week 0) 
Table 1

Baseline characteristics of the study cohort

\begin{tabular}{|c|c|c|c|}
\hline & Anti-TNF $(n=49)$ & Vedolizumab $(n=111)$ & $p$ value \\
\hline Mean age, years & 33 & 37 & 0.049 \\
\hline Female sex, $n(\%)$ & $23(46.9)$ & $58(52.3)$ & 0.535 \\
\hline Type of IBD & & & 0.069 \\
\hline Crohn's disease, $n(\%)$ & $34(69.4)$ & $60(54.5)$ & \\
\hline Ulcerative colitis, $n(\%)$ & $15(30.6)$ & $51(45.6)$ & \\
\hline Mean duration of IBD, years & 5 & 11 & 0.001 \\
\hline Smoking status & & & 0.421 \\
\hline Never, $n(\%)$ & 38 (77.6) & $74(67.3)$ & \\
\hline Past, $n(\%)$ & $9(18.4)$ & $30(27.3)$ & \\
\hline Current, $n(\%)$ & $2(4.1)$ & $6(5.5)$ & \\
\hline Median SIBDQ score (95 \% CI) & $47(31-67)$ & $46(28-66)$ & 0.633 \\
\hline \multicolumn{4}{|l|}{ Medical history } \\
\hline Insomnia, $n(\%)$ & $7(14.3)$ & $16(14.4)$ & 0.983 \\
\hline Depression, $n(\%)$ & $10(20.4)$ & $19(17.12)$ & 0.618 \\
\hline Anxiety, $n(\%)$ & $5(10.20)$ & $15(13.5)$ & 0.560 \\
\hline Median HBI score $(95 \%$ CI) & $4(0-16)$ & $6(1-15)$ & 0.008 \\
\hline Mean SCCAI score & $5.9 \pm 4.2$ & $5.9 \pm 3.1$ & 0.991 \\
\hline Median CRP, mg/L (95 \% CI) & $2.6(0.2-69.7)$ & $6.2(0.3-53.5)$ & 0.530 \\
\hline Median ESR, mm/h (95 \% CI) & $13(2-55)$ & $15(2-88)$ & 0.370 \\
\hline Median WBC, K/uL (95\% CI) & $7.8(4.8-14.1)$ & $8.1(4.3-15.4)$ & 0.924 \\
\hline Median HGB, g/dL (95 \% CI) & $13.2(10.8-15.6)$ & $12.9(8.8-15.8)$ & 0.205 \\
\hline Baseline sleep disturbance symptoms ${ }^{a}, n(\%)$ & $27(55.1)$ & $43(38.7)$ & 0.840 \\
\hline Baseline depressive symptoms ${ }^{b}, n(\%)$ & $22(44.9)$ & $41(36.9)$ & 0.351 \\
\hline Baseline anxiety symptoms ${ }^{c}, n(\%)$ & $26(53.1)$ & $48(43.2)$ & 0.283 \\
\hline \multicolumn{4}{|l|}{ Baseline medication use } \\
\hline Steroids, $n(\%)$ & $25(51.0)$ & $42(37.8)$ & 0.119 \\
\hline 5-Aminosalicylates, $n(\%)$ & $10(20.4)$ & $30(27.0)$ & 0.373 \\
\hline Immunomodulators, $n(\%)$ & $11(22.5)$ & $41(36.9)$ & 0.071 \\
\hline Opioid, $n(\%)$ & $6(12.2)$ & $17(15.3)$ & 0.610 \\
\hline Sleep aid, $n(\%)$ & $9(18.4)$ & $20(18.0)$ & 0.958 \\
\hline Depression treatment ${ }^{d}, n(\%)$ & $11(22.5)$ & $28(25.2)$ & 0.706 \\
\hline Prior anti-TNF, $n(\%)$ & $7(14.3)$ & $99(89.2)$ & $<0.001$ \\
\hline Ileal pouch-anal anastomosis, $n(\%)$ & $3(6.1)$ & $5(4.5)$ & 0.665 \\
\hline Stoma, $n(\%)$ & $1(2.0)$ & $9(8.1)$ & 0.144 \\
\hline
\end{tabular}

Dig Dis Sci. Author manuscript; available in PMC 2018 January 01. 
${ }^{d}$ Depression treatment was defined as receiving a tricyclic antidepressant, selective serotonin reuptake inhibitor, or cognitive behavioral therapy 
Table 2

Factors associated with sleep quality at baseline

\begin{tabular}{|c|c|c|c|}
\hline & Co-efficient & CI $(95 \%)$ & $p$ value \\
\hline Type of therapy (anti-TNF $=$ reference) & 2.76 & -0.88 to 6.39 & 0.136 \\
\hline Age & 0.09 & -0.30 to 0.21 & 0.142 \\
\hline Sex $($ male $=$ reference $)$ & 0.36 & -3.24 to 3.96 & 0.844 \\
\hline Type of IBD $(\mathrm{CD}=$ reference $)$ & 0.33 & -3.30 to 3.97 & 0.857 \\
\hline Duration of IBD & 0.05 & -0.11 to 0.22 & 0.522 \\
\hline \multicolumn{4}{|l|}{ Smoking status $($ never $=$ reference $)$} \\
\hline Past & 0.44 & -3.92 to 4.81 & 0.842 \\
\hline Current & 8.70 & 0.60 to 16.82 & 0.036 \\
\hline Baseline activity & 0.53 & 0.07 to 1.00 & 0.026 \\
\hline $\mathrm{CRP}, \mathrm{mg} / \mathrm{L}$ & -0.03 & -0.11 to 0.05 & 0.423 \\
\hline $\mathrm{ESR}, \mathrm{mm} / \mathrm{h}$ & -0.002 & -0.08 to 0.08 & 0.957 \\
\hline $\mathrm{WBC}, \mathrm{K} / \mathrm{uL}$ & 0.11 & -0.50 to 0.73 & 0.719 \\
\hline $\mathrm{HGB}, \mathrm{g} / \mathrm{dL}$ & 0.04 & -0.94 to 1.02 & 0.932 \\
\hline Baseline depressive symptoms ${ }^{a}$ & 5.37 & 1.97 to 8.77 & 0.002 \\
\hline Baseline anxiety symptoms $b$ & 6.31 & 2.83 to 9.78 & 0.000 \\
\hline \multicolumn{4}{|l|}{ Baseline medication use } \\
\hline Steroids & 0.67 & -2.95 to 4.28 & 0.715 \\
\hline 5-Aminosalicylates & 0.36 & -3.70 to 4.43 & 0.860 \\
\hline Immunomodulators & -0.27 & -4.10 to 3.56 & 0.888 \\
\hline Opioids & 4.98 & 0.09 to 9.86 & 0.046 \\
\hline Depression treatment & 4.93 & 0.92 to 8.94 & 0.016 \\
\hline
\end{tabular}

${ }^{a}$ Depressive symptoms were defined as having a PROMIS depression T-score greater than 50

${ }^{b}$ Anxiety symptoms were defined as having a PROMIS anxiety T-score greater than 50

Dig Dis Sci. Author manuscript; available in PMC 2018 January 01. 


\section{Table 3}

Comparison of disease activity and psychosocial outcomes based on remission status at week 14

\begin{tabular}{|c|c|c|c|}
\hline & Active disease $(n=60)$ & Disease in remission $(n=55)$ & $p$ value \\
\hline Median HBI score at follow-up (95 \% CI) & $7(5-20)$ & $2(0-4)$ & $<0.001$ \\
\hline Mean SCCAI score at follow-up (SD) & $4.9 \pm 1.8$ & $1.2 \pm 0.8$ & $<0.001$ \\
\hline Median CRP at follow-up, mg/L (95\% CI) & $3.8(0.6-34)$ & $2.3(0.2-56.6)$ & 0.047 \\
\hline Sleep disturbance symptoms ${ }^{a}$ at follow-up, $n(\%)$ & $31(56.4)$ & $13(30.2)$ & 0.010 \\
\hline Depressive symptoms at follow-up $b, n(\%)$ & $26(47.3)$ & $8(18.2)$ & 0.002 \\
\hline Anxiety symptoms at follow-up ${ }^{c}, n(\%)$ & $31(56.4)$ & $15(34.1)$ & 0.027 \\
\hline
\end{tabular}

${ }^{a}$ Sleep disturbance symptoms were defined as having a PROMIS sleep disturbance T-score greater than 50

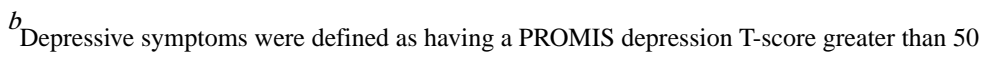

${ }^{c}$ Anxiety symptoms were defined as having a PROMIS anxiety T-score greater than 50 